\title{
A (in)visibilidade da mulher negra youtuber
}

\section{The (in)visibility of the black female youtuber}

\section{La (in)visibilidad de la mujer negra youtuber}

\author{
Géssica de Castro Silva Viana ${ }^{1, a}$ \\ gessicaadecastro@gmail.com | https://orcid.org/oooo-0oo3-2483-4889 \\ Fernanda Ariane Silva Carrera ${ }^{2, b}$ \\ fernandacarrera@gmail.com | https://orcid.org/oooo-0001-5024-0860 \\ ${ }^{1}$ Universidade Federal do Rio Grande do Norte. Natal, RN, Brasil. \\ ${ }^{2}$ Universidade Federal do Rio de Janeiro. Rio de Janeiro, RJ, Brasil. \\ a Mestrado em Estudos da mídia pela Universidade Federal do Rio Grande do Norte.

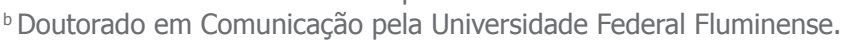

\section{Resumo}

Discutindo sob o viés interseccional, o artigo busca expor a problemática da invisibilidade midiática das mulheres negras youtubers dentro do contexto da cultura participativa. Identificamos e observamos canais de mulheres youtubers a partir do recorte das temáticas do feminismo e empoderamento feminino, e realizamos um estudo descritivo com abordagem quanti-qualitativa, analisando as aproximações e distanciamentos dos canais a partir das categorias de alcance, interação e temática. Conclui-se que as youtubers negras interagem de forma mais significativa do que as youtubers não negras, o que não interfere no alcance dos canais, visto que as youtubers negras possuem dados de alcance inferior às youtubers não negras. Observamos que mesmo podendo atingir todas as mulheres, as falas das youtubers negras podem ser entendidas com enfoque na questão racial, enquanto isso, identificamos um discurso universal do 'ser mulher' nas falas das youtubers não negras, fator que pode contribuir para o alcance expressivo.

Palavras-chave: YouTube; Mulheres negras; Visibilidade; Interseccionalidade; Empoderamento.

\begin{abstract}
Discussing under the intersectional bias, the article seeks to expose the problem of media invisibility of black women youtubers within the context of participatory culture. We identified and observed channels of female youtubers from the cut of the themes of feminism and female empowerment, and we conducted a descriptive study with quantitative and qualitative approach, analyzing the approximations and distances of the channels from the reach, interaction and thematic categories. It is concluded that black youtubers interact more significantly than non-black youtubers, which does not interfere with the range of the channels, as black youtubers have lower range data than non-black youtubers. We note that even though it can reach all women, the black youtubers' speeches can be understood with focus on the racial issue, meanwhile, we identified a universal discourse of 'being a woman' in the non-black youtubers speeches, a factor that can contribute to the expressive reach .
\end{abstract}

Keywords: YouTube; Black women; Visibility; Intersectionality; Empowerment. 


\section{Resumen}

Discutiendo bajo el sesgo interseccional, el artículo busca exponer el problema de la invisibilidad mediática de las youtubers negras en el contexto de la cultura participativa. Identificamos y observamos canales de youtubers mujeres a partir del corte de los temas del feminismo y el empoderamiento femenino, y realizamos un estudio descriptivo con enfoque cuantitativo y cualitativo, analizando las aproximaciones y distancias de los canales desde el alcance, la interacción y las categorías temáticas. Se concluye que las youtubers negras interactúan de manera más significativa que las youtubers no negras, lo que no interfiere con el rango de los canales, ya que las youtubers negras tienen datos de rango más bajos que las youtubers no negras. Observamos que, aunque puede llegar a todas las mujeres, los discursos de las youtubers negras se pueden entender con un enfoque en el tema racial, mientras que identificamos un discurso universal de 'ser mujer' en los discursos de las youtubers no negras, un factor que puede contribuir al alcance expresivo.

Palabras clave: Youtube; Mujeres negras; Visibilidad; Interseccionalidad; Empoderamiento.

Este artigo faz parte do dossiê Saúde, etnicidades e diversidade cultural: comunicação, territórios e resistências.

Contribuição dos autores:

Concepção e desenho do estudo: Géssica de Castro Silva Viana, Fernanda Ariane Silva Carrera.

Aquisição, análise ou interpretação dos dados: Géssica de Castro Silva Viana.

Redação do manuscrito: Géssica de Castro Silva Viana, Fernanda Ariane Silva Carrera.

Revisão crítica do conteúdo intelectual: Géssica de Castro Silva Viana, Fernanda Ariane Silva Carrera.

Declaração de conflito de interesses: não há.

Fontes de financiamento: Programa de Demanda Social da Coordenação de Aperfeiçoamento de Pessoal de Nível Superior (Capes).

Considerações éticas: não há.

Agradecimentos/Contribuições adicionais: não há.

Histórico do artigo: submetido: 12 ago. 2019 | aceito: 1 out. 2019 | publicado: 20 dez. 2019.

Apresentação anterior: o artigo apresenta resultados da dissertação de mestrado intitulada 'Ciberfeminismo e a (in)visibilidade da mulher negra youtuber', defendida no Programa de Pós-graduação em Estudos da Mídia da Universidade Federal do Rio Grande do Norte, em junho de 2019.

Licença CC BY-NC atribuição não comercial. Com essa licença é permitido acessar, baixar (download), copiar, imprimir, compartilhar, reutilizar e distribuir os artigos, desde que para uso não comercial e com a citação da fonte, conferindo os devidos créditos de autoria e menção à Reciis. Nesses casos, nenhuma permissão é necessária por parte dos autores ou dos editores. 


\section{Introdução}

A possibilidade de criar perfis no ciberespaço com a possibilidade de produzir, consumir e disseminar conteúdos diversos para pessoas de lugares e contextos diferentes traz discussões e problemáticas que geralmente não possuíam espaço na mídia tradicional. A cultura participativa tem como premissa a interação e disseminação de conteúdos, em que produtores e consumidores se misturam e constroem um novo modelo de participação no consumo cultural ${ }^{1}$, porém, mesmo a partir desses novos modelos de produção midiática, é inegável que as dificuldades em acesso e participação continuem existindo. É importante, portanto, ressaltar que ela é participativa em relação aos modos antigos de comunicação e não em termos absolutos. O que não se pode negar são as inúmeras vantagens relacionadas às questões sociais que estão diretamente ligadas ao avanço tecnológico e às novas relações sociais no ambiente online. Essas mudanças fazem com que a internet não seja utilizada somente "[...] como fonte de material, mas principalmente como fonte de divulgação de conteúdo, dessa forma o ciberespaço oficializa o direito do público, até então passivo, de contribuir ativamente com a construção de sua própria cultura" ${ }^{2}$, permitindo com que esses sujeitos formem uma rede de diálogo a partir de suas narrativas.

As pessoas negras fazem parte desses grupos de indivíduos que, por muitas vezes, não possuíam espaço em outros meios de comunicação, ou eram acometidos por representações estereotipadas. Silvio Almeida ${ }^{3}$ nos diz que do mesmo modo que o privilégio faz o indivíduo branco, são as desvantagens sociais - e não somente a cor de pele - que fazem o indivíduo negro. Essas desigualdades estão postas dentro de práticas do cotidiano e em diversas esferas da sociedade, não excluindo a esfera midiática. A ligação direta entre a mídia e uma sociedade patriarcal supremacista branca faz com que as representações negativas de imagens dos sujeitos negros sejam naturalizadas e perpetuadas no imaginário social", mantendo "a opressão, a exploração e a dominação de todas as pessoas negras em diversos aspectos"4.

As produções midiáticas não representam a realidade, mas sim "uma representação do imaginário social acerca de pessoas negras"3, comprovando que a ideologia ali exibida não é uma representação da realidade concreta, mas sim das relações que temos com essas realidades concretas. No entanto, Kabengele Munanga ${ }^{5}$ diz que embora o racismo tenha engendrado o "segregacionismo, por outro lado sua dinâmica permitiu a construção de identidades raciais e étnicas fortes no campo dos oprimidos desses sistemas"5. Para o autor, os movimentos negros estão associados na reconstrução e afirmação de uma identidade racial e/ou cultural, servindo como "plataforma mobilizadora no caminho da conquista de sua plena cidadania"5. Essa plataforma mobilizadora aqui comentada por Munanga não age somente no movimento negro, ela se enraíza entre outros movimentos que reivindicam por direitos igualitários, na busca por cidadania e equidade.

Sendo assim, atualmente essas representações midiáticas ou a inexistência delas estão sendo cada vez mais discutidas. A utilização da internet e principalmente das redes sociais ${ }^{6}$ atualmente vem proporcionando uma discussão sobre esse sistema de poder hegemônico articulado pela branquitude heteronormativa. A busca pela crítica de si mesmo e pela tentativa de modos para redefinir as estruturas está entre os assuntos mais discutidos nas redes.

A nova reconfiguração que vem sendo desenvolvida por meio dessas discussões nos mostra como questões de raça, gênero e classe se expandem como críticas à estrutura e modos de apropriar-se do poder sobre sua própria existência. A definição de empoderamento segue "próxima da noção de autonomia, pois se refere à capacidade de os indivíduos e grupos poderem decidir sobre as questões que lhes dizem respeito" 7 , trazer para o centro do debate as discussões que interagem com suas subjetividades, "numa perspectiva emancipatória, empoderar é o processo pelo qual indivíduos, organizações e comunidades angariam recursos que lhes permitam ter voz, visibilidade, influência e capacidade de ação e decisão" 7 . Nessa esfera contextual do empoderar-se, as mulheres negras se destacam, uma vez que sempre foram agentes ativos na tentativa de movimentar a estrutura que as aprisiona ${ }^{8}$. Na conjuntura de uma "cultura atrelada às tecnologias digitais" ${ }^{9}$, poderíamos enxergar, talvez, 
um novo local para ecoar essas vozes que há muito tentam falar e são silenciadas. A utilização dos sites de redes sociais para o compartilhamento de momentos e angústias pessoais, fomentando a discussão sobre o racismo, se alastra de forma crescente, revelando mulheres negras cada vez mais conectadas, seja pelo consumo ou pela produção de conteúdos envoltos em contestação, coletivização e subjetividade.

No entanto, ao verificarmos, por exemplo, o ranking dos 100 maiores youtubers do Brasil, disponibilizado no site Social Blade, observamos a inexpressiva quantidade de canais femininos na lista, além da total ausência de canais de mulheres negras. Nesse sentido, é possível refletir: embora seja possível reconhecer a emergência de vozes antes silenciadas pelas potencialidades da materialidade tecnológica do ambiente digital; embora seja evidente o caráter inclusivo e transformador do ciberativismo ${ }^{10}$ e a efervescência da discussão sobre empoderamento e luta por reconhecimento, a estrutura sociocultural machista e racista ainda parece ecoar com forte impacto em novos ambientes de consumo e sociabilidade.

O presente artigo busca, portanto, a partir de um estudo descritivo com abordagem quanti-qualitativa, expor e evidenciar dados estatísticos de alcance midiático entre canais de youtubers negras e não negras, analisando as temáticas dos canais sob o viés interseccional além de explicitar as interações das youtubers com sua audiência. Dentro da vasta possibilidade de conteúdos dentro do Youtube, definimos trabalhar nessa pesquisa com o recorte de canais que possuem como temática o feminismo e o empoderamento feminino. Isto é, em um contexto de temática semelhante, quais vídeos geram mais participação e engajamento? Quais youtubers conquistam maior alcance e compartilhamento dos seus conteúdos? Quais conseguem ultrapassar os limites do espaço digital e ocupar espaços midiáticos tradicionais? Em uma conjuntura de maioria preta e parda ${ }^{11}$, seria possível considerar a identificação como um fator preponderante, colocando os conteúdos gerados por essa população em lugar de maior visibilidade. No entanto, parte-se do pressuposto que a falta de alcance e a invisibilidade midiática atribuída a esses atores e seus produtos emergem da suposta "neutralidade" ${ }^{12}$ associada à branquitude.

\section{Enegrecendo a rede}

No ambiente digital, é possível perceber uma crescente ocupação de mulheres negras em espaços de projeção e discussão de temáticas pertinentes, como um processo de emancipação e conclamação para a potência de suas vozes. Muitas se apropriam destes ambientes com o intuito de promoverem o debate sobre suas próprias subjetividades, mas também como modo de propagar discursos anti-hegemônicos, antirracistas e antissexistas.

A discussão sobre a estética, aliás, é uma das formas preponderantes de manifestação desses discursos, contestando uma dinâmica dominante do padrão de beleza branco.

Para Berth ${ }^{13}$, os cabelos são elementos importantes quando discutimos a questão de autoestima e amor próprio, principalmente para as mulheres, mas "esse estigma recai sobre os ombros de mulheres negras desde a mais tenra infância, pois nossos cabelos são alvo constante de diversas injúrias, rejeições e manifestações racistas, esteja ele alisado ou natural"13.

No Facebook, temos alguns grupos que estão há alguns anos discutindo a transição capilar - processo no qual se interrompe o uso de produtos químicos no cabelo, com a finalidade de chegar à sua textura natural. O grupo Cacheadas em transição (Oficial 2012), por exemplo, possui quase 260 mil membros - em sua maioria mulheres - que entre fotos de referências, dicas de produtos e outros conteúdos relacionados ao cabelo crespo/cacheado, também escrevem desabafos sobre a dificuldade de passar pela transição capilar, remetendo ao racismo inserido na sociedade os problemas de interromper a utilização de produtos químicos que alisavam seus cabelos e retornarem à sua textura natural. Essa discussão em especial também reverberou no Youtube, onde podemos ver vários canais falando a respeito da transição capilar, incentivando mais pessoas - mulheres, principalmente - a assumirem e aceitarem seus cabelos naturais. Canais como os 
das youtubers Rayza Nicácio e Ana Lídia Lopes foram, de certa forma, importantes para a propagação da aceitação e valorização do cabelo crespo/cacheado.

A discussão a respeito da estética no Youtube - principalmente do cabelo crespo/cacheado - é uma das manifestações do aumento significativo do debate sobre as subjetividades das mulheres negras, mas outros espaços e outras ocupações do ambiente digital também são fundamentais para a proliferação da discussão e do empoderamento, como alguns sites e blogs. O Geledés - Instituto da Mulher Negra, por exemplo, é uma ONG fundada em 1988 que "se posiciona em defesa de mulheres e negros por entender que esses dois segmentos sociais padecem de desvantagens e discriminações no acesso às oportunidades sociais em função do racismo e do sexismo vigentes na sociedade brasileira"14.

O Portal Geledés, então, produz conteúdos em prol de uma discussão interseccional, a partir da contribuição de pessoas negras, propagando discussões e materiais que também são disponibilizados em outras mídias sociais, como Facebook e Instagram. Do ponto de vista da interseccionalidade, portanto, raça, classe e gênero devem ser discutidos como variáveis fundamentais na construção das experiências sociais. Para Angela Davis "a raça é a maneira como a classe é vivida. Da mesma forma que gênero é a maneira como a classe é vivida” ${ }^{15}$, refletindo como a ligação de determinados marcadores de diferenças produziam opressões distintas. É “[...] importante para os feminismos desvencilharem-se da noção de que há uma qualidade universal que podemos chamar de mulher"16, uma vez que elas possuem questões específicas que não são atendidas apenas nas discussões de gênero. Para Christofoletti e Watzko ${ }^{17}$, “[...] em face dessa dupla desvalorização, as mulheres negras são a fatia mais marginalizada da sociedade" ${ }^{17}$, vivenciando uma série exponencial de práticas discriminatórias. Para Carneiro ${ }^{8}$, a categorização da universalização do "ser mulher" reduzia todas as mulheres às mesmas demandas, como se não houvesse nenhuma diferença que pudesse restringir um direito de uma sob outra.

A discussão acerca do feminismo interseccional surge a partir de ativistas negras não conformadas com as pautas do feminismo branco ${ }^{18}$. Kimberlé Crenshaw $^{19}$ levantou o questionamento a respeito do olhar singular que não identificava que existiam outros marcadores, como por exemplo a raça, que estavam diretamente ligados na discussão do feminismo. Para a autora "a interseccionalidade pode servir de ponte entre diversas instituições e eventos e entre questões de gênero e de raça nos discursos acerca dos direitos humanos"19.

Alguns anos depois, Patrícia Collins ${ }^{20}$ traz essa discussão novamente e define o conceito de interseccionalidade como um modo de compreensão e análise das situações sociais em toda a sua complexidade, destacando que nenhum fenômeno pode ser influenciado de forma unilateral. A autora propõe pensar a interseção das desigualdades, em uma "matriz de dominação" ${ }^{21}$ que prevê um entrecruzamento das experiências no contexto complexo de opressões ${ }^{21}$. Isto é, "quando se trata de desigualdade social, a vida das pessoas e a organização do poder em uma dada sociedade são mais bem entendidas como sendo moldadas não por um único eixo de divisão social, [...] mas muitos eixos que trabalham juntos e influenciam um ao outro" ${ }^{20}$, como os marcadores de diferenças mencionados: raça, gênero e classe, dessa maneira "a interseccionalidade como ferramenta analítica permite às pessoas um melhor acesso à complexidade do mundo e de si mesmas"20.

No ciberespaço, estes ideais interseccionais estão sendo propagados por meio de ferramentas de exposição de subjetividades e de construção coletiva, como os blogs. Estes espaços foram e são elementos de forte ligação entre as tecnologias digitais e o feminismo. O projeto Blogagem Coletiva da Mulher Negra, que possuía o objetivo de incentivar a produção de textos por mulheres negras, foi o criador do blog Blogueiras Negras, que possui como missão "promover a livre produção de conteúdo, partindo do princípio que às mulheres negras sempre foi negado lugares e discursos. Queremos dar visibilidade aos nossos assuntos e nos tornarmos protagonistas de nossas lutas e vidas" ${ }^{22}$, o que podemos encaixar ou definir como uma ferramenta de empoderamento. A tomada de consciência que Paulo Freire ${ }^{23}$ destaca pode ser encontrada aqui, nessa perspectiva, como uma ferramenta de propagação de suas vozes, buscando alcançar um lugar que sempre foi negado. São mudanças que a passos pequenos desencadeiam uma séria de discussões importantes para 
as mulheres negras. $\mathrm{O}$ fato de hoje podermos debater com maior facilidade sobre nossas subjetividades já nos abre um leque infinito de opções de aprendizado, crítica e autocuidado.

É importante ressaltar que as temáticas a respeito das mulheres negras são diversas, desde aceitação e cuidados com o cabelo afro, combate à hipersexualização do corpo, inserção no mercado de trabalho, solidão, genocídio etc. São fatores que além de possuírem o marcador da raça, também possuem o de gênero e classe. Djamila Ribeiro (filósofa com importante presença on-line e incentivadora do debate no ambiente digital) desenvolve a importância de se produzir esse debate interseccional, uma vez que, enquanto o feminismo tiver como enfoque apenas a luta contra o sexismo, as mulheres negras, mulheres lésbicas, mulheres trans e outras irão continuar sem lugar de fala e de luta. É “importante notar que, ao pensar a interseccionalidade, as mulheres negras não estão pensando somente nas opressões que as afligem, o que transcende o discurso de uma luta meramente identitária: elas estão pensando um novo modelo de sociedade"24.

Vê-se, portanto, que há o esforço de ocupação de espaços discursivos de destaque na contemporaneidade, materializados por lugares de produção e compartilhamento de conteúdos digitais, buscando pensar nestes novos modelos sociais. No Youtube, há uma diversidade de canais femininos e negros que abordam essa temática, possibilitando a criação de uma rede de diálogo a partir de suas especificidades. No entanto, o fato de possuir um espaço de debate não parece ser o suficiente para fazer com que essas mulheres possuam alcance midiático eficiente, ou igual a outras youtubers, como será exposto aqui.

\section{Mapeando as narrativas}

Com o intuito de revelar o caráter desigual da visibilidade dos conteúdos de youtubers negras e não negras, portanto, inicialmente realizamos um mapeamento dos canais mais relevantes no Youtube que abordassem a temática do feminismo e empoderamento feminino. Dessa forma, a finalidade é trazer um recorte pela temática, ajudando a revelar a desigualdade no alcance e na visibilidade dos conteúdos produzidos por sujeitos diferentes. Optamos por uma pesquisa exploratória em sites da internet que produzem listas indicando os canais pela temática, além de pesquisas na própria plataforma de vídeo. Estabelecemos relações entre as listas e identificamos os canais mais relevantes dentro da plataforma que trabalham com a temática em questão, exibidos no Quadro 1. 
Quadro 1 - Canais que discutem feminismo e empoderamento feminino

\begin{tabular}{|l|l|l|l|l|l|}
\hline Canal & Inscritos & Visualizações & Canal & Inscritos & Visualizações \\
\hline Acidez feminina & 1.589 .236 & 193.199 .754 & Lully de verdade & 366.333 & 16.007 .010 \\
\hline Afros e afins & 440.936 & 16.933 .542 & Mais magenta & 22.622 & 705.481 \\
\hline Alexandrismos & 341.049 & 15.220 .586 & Mulheres de luta & 1.662 & 67.829 \\
\hline Ana Paula Xongani & 55.224 & 1.185 .348 & Não me Kahlo & 3.162 & 171.328 \\
\hline Azmina & 5.889 & 1.355 .439 & Neggata & 58.208 & 1.661 .945 \\
\hline Barraco da Rosa TV & 31.235 & 935.968 & $\begin{array}{l}\text { Nós, mulheres da } \\
\text { periferia }\end{array}$ & 258 & 8.135 \\
\hline Blogueiras negras & 1.747 & 32.569 & $\begin{array}{l}\text { Nunca te pedi } \\
\text { nada }\end{array}$ & 1.187 .326 & 95.319 .572 \\
\hline Canal das bee & 357.666 & 31.358 .389 & $\begin{array}{l}\text { O mundo segundo } \\
\text { Ana Roxo }\end{array}$ & 26.892 & 1.465 .884 \\
\hline Coisas de preta & 59.839 & 3.063 .024 & Põe na roda & 870.424 & 122.992 .521 \\
\hline De pretas & 336.801 & 10.044 .833 & Preta pariu & 61.853 & 2.627 .380 \\
\hline ElloraHaonne & 1.035 .721 & 40.020 .458 & Rayza Nicácio & 1.581 .144 & 101.901 .145 \\
\hline Hysteria & 23.752 & 1.333 .150 & Soul vaidosa & 51.248 & 1.210 .848 \\
\hline JacyJully & 148.177 & 8.469 .470 & Stephanie Noelle & 48.885 & 2.122 .575 \\
\hline Jana Viscardi & 21.837 & 799.200 & Tá querida! & 477.667 & 25.177 .183 \\
\hline JoutJout Prazer & 1.918 .769 & 232.397 .905 & Think Olga & 19.363 & 364.883 \\
\hline Joyce Show & 5.457 & 112.578 & Tia Má & 78.046 & 3.697 .652 \\
\hline Louie Ponto & 434.203 & 12.715 .831 & $\begin{array}{l}\text { Um abadá para } \\
\text { cada dia }\end{array}$ & 9.349 & 394.986 \\
\hline Luci Gonçalves & 210.849 & 9.360 .810 & Victoria Ferreira & 145.749 & 6.321 .832 \\
\hline Lugar de mulher & 3.466 & 34.627 & $\begin{array}{l}\text { Você é feminista e } \\
\text { não sabe }\end{array}$ & 4.630 & 128.633 \\
\hline
\end{tabular}

Fonte: As autoras (2018).

Buscando compreender as temáticas abordadas por esses canais aqui mencionados, foi realizada uma coleta de dados no período de março a setembro de 2018, onde foram analisados todos os vídeos postados desde a criação dos canais das youtubers até o mês de agosto de 2018. Como nossa intenção é a de trabalhar a visibilidade da mulher youtuber, optamos por escolher apenas canais de ações individuais ${ }^{25}$, dessa forma, a participação de canais que são apresentados por duplas ou grupos não se fazem interessante para a análise. Outro aspecto levado em consideração nessa triagem foi a regularidade em que os vídeos são postados, sendo assim, canais nos quais as últimas publicações aconteceram há mais de dois meses da coleta dos dados foram dispensados. Além disso, buscando estabelecer uma parcial coerente estatisticamente na análise, os canais que possuem menos de 50 mil inscritos e menos de 100 vídeos publicados também foram retirados do quadro.

Sendo assim, chegamos a uma relação de 14 canais, exibidos nos Quadros 2 e 3, que, dentro da diversidade de conteúdos abordados, possuem a questão do feminismo e empoderamento feminino como uma das principais temáticas. É importante salientar que as youtubers negras que estamos mencionando nessa pesquisa são mulheres que se autodeclaram negras. 
Quadro 2 - Youtubers negras

\begin{tabular}{|l|l|}
\hline Canal & Youtuber \\
\hline Afros e afins & Nátaly Neri \\
\hline Ana Paula Xongani & Ana Paula Xongani \\
\hline De Pretas & Gabi Oliveira \\
\hline JacyJully & Jacy Jully \\
\hline Luci Gonçalves & Luci Gonçalves \\
\hline RayzaNicácio & Rayza Nicácio \\
\hline Soul Vaidosa & Xan Ravelli \\
\hline Tia Má & Maíra Azevedo \\
\hline
\end{tabular}

Fonte: As autoras (2018).

Quadro 3-Youtubers não negras

\begin{tabular}{|l|l|}
\hline Canal & Youtuber \\
\hline Alexandrismos & Alexandra Gurgel \\
\hline Ellora Haonne & Ellora Haonne \\
\hline JoutJout Prazer & Júlia Tolezano \\
\hline Nunca te pedi nada & Maíra Medeiros \\
\hline Tá, querida & Luiza Junqueira \\
\hline Victoria Ferreira & Victoria Ferreira \\
\hline
\end{tabular}

Fonte: As autoras (2018).

Realizando método descritivo, podemos estabelecer uma relação comparativa entre os canais, por meio dos dados fornecidos pelo próprio Youtube, como quantidade de inscritos e a média de visualizações. Detectamos logo de início a diferença significativa de alcance entre youtubers negras e não negras, como podemos verificar nas Figuras 1 e 2. O alcance, aqui, é medido por meio das visualizações e do número de inscritos nos canais. 


\begin{tabular}{|c|c|c|}
\hline Afros e afins & 16.933 .542 & \\
\hline Alexandrismos & 15.220 .586 & \\
\hline Ana Paula Xongani & 1.185 .348 & \\
\hline De pretas & 10.044 .833 & \\
\hline Ellora Haonne & 40.020 .458 & \\
\hline Jacy Jully & 8.469 .470 & \\
\hline Jout Jout Prazer & & \\
\hline Luci Gonçalves & 9.360 .810 & 232.397 .905 \\
\hline Nunca te pedi nada & 95.319 .572 & \\
\hline Rayza Nicácio & \begin{tabular}{|l|l|}
101.901 .145 \\
\end{tabular} & \\
\hline Soul Vaidosa & 1.210 .848 & \\
\hline Tá querida & 25.177 .183 & \\
\hline Tia Má & 3.697 .652 & \\
\hline Victoria Ferreira & 6.321 .832 & \\
\hline
\end{tabular}

Figura 1 - Visualizações

Fonte: As autoras (2018).

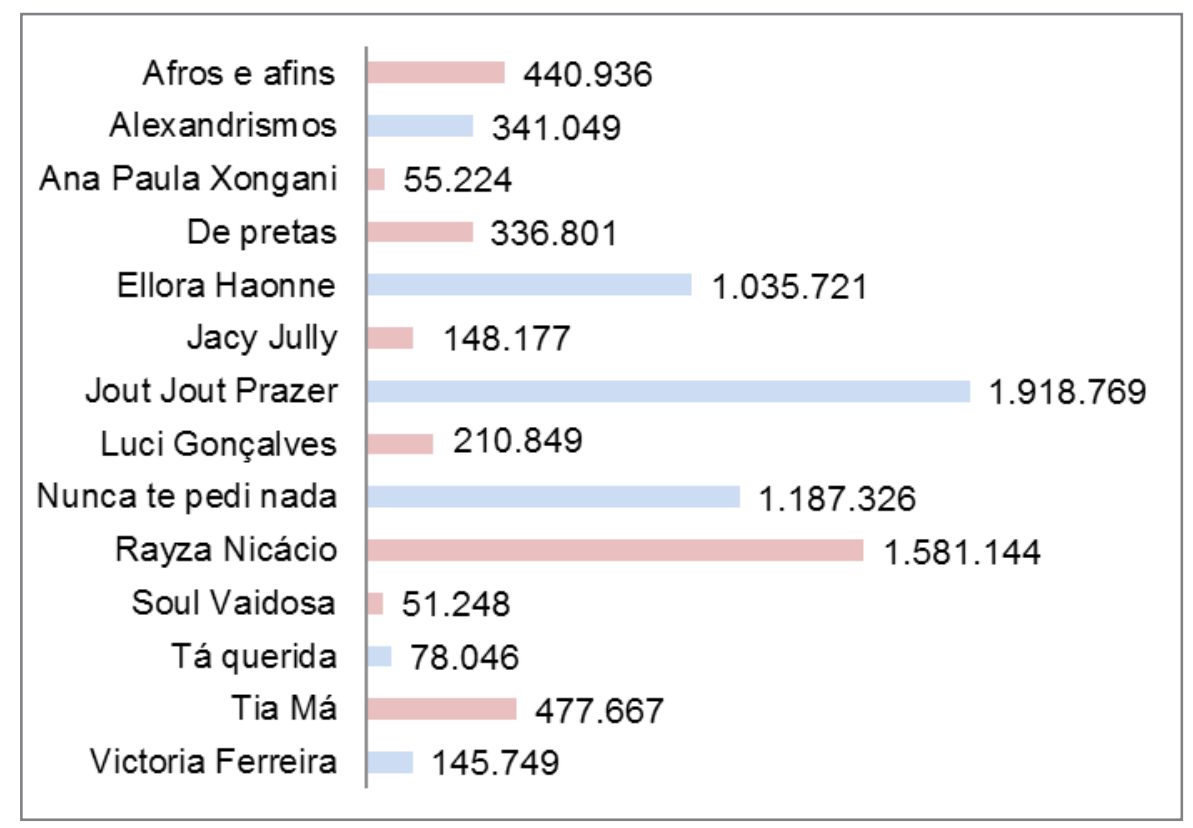

Figura 2 - Inscritos

Fonte: As autoras (2018).

Partindo desses dados, o passo seguinte foi a realização de um levantamento das subtemáticas abordadas e suas intersecções nos 14 canais, a fim de estabelecer uma amostragem menor para a pesquisa. Buscamos conjuntamente identificar os canais que dedicam mais espaço e conteúdo para o recorte central da pesquisa. 


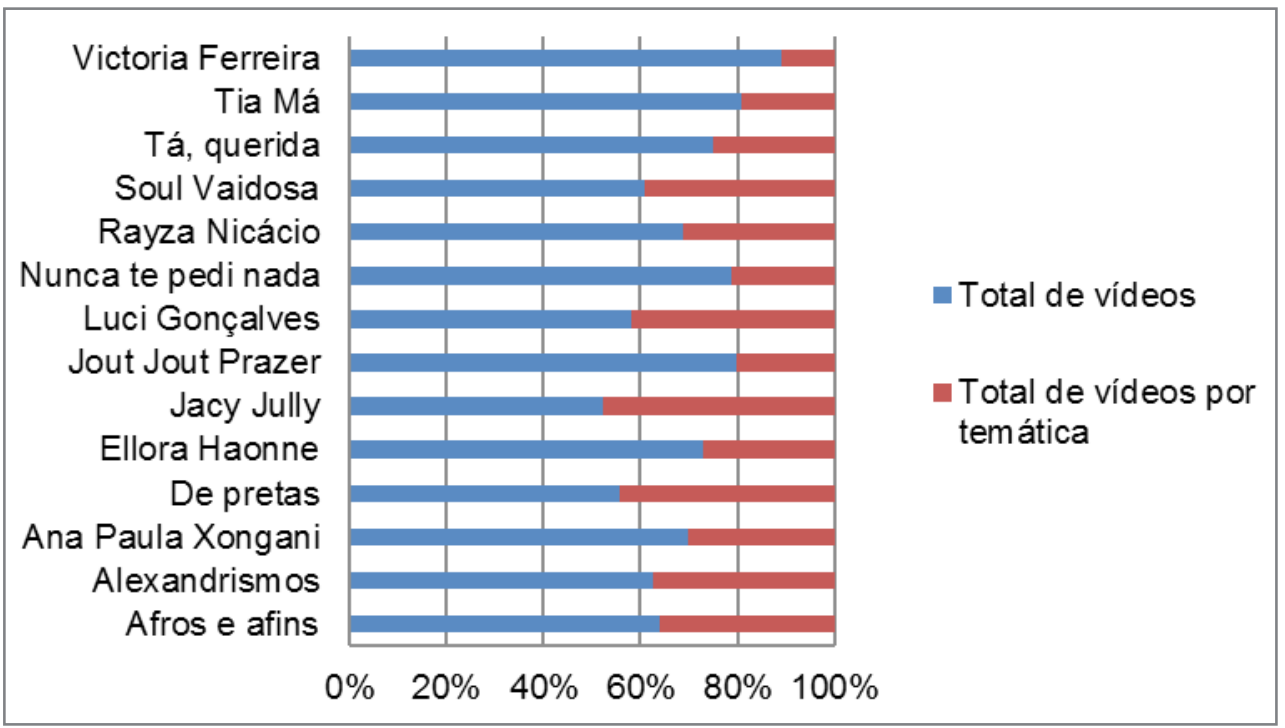

Figura 3 - Total de vídeos por temática Fonte: As autoras (2018).

Considerando que a temática do feminismo e empoderamento feminino incluem as questões do corpo, a partir da discussão da quebra de padrões estéticos estabelecidos pela sociedade, optamos por selecionar os canais que produzem críticas a esses padrões de beleza, além de discutir as questões do machismo e os lugares em que as mulheres são acometidas pela opressão de gênero - e que conjuntamente trazem a discussão da saúde mental e do autocuidado - mas compreendemos que o ato de assumir uma postura mais crítica em relação às questões sociais também dificulta o acesso dessas youtubers a lugares privilegiados. Observamos todos os 14 canais e estabelecemos um recorte de seis para essa pesquisa, sendo três youtubers negras e três youtubers não negras (Quadro 4). A definição dos canais foi realizada com base em dois critérios: o primeiro foi o da assiduidade de vídeos destinados a essa temática (Figura 3) e o segundo foi o alcance, revelado pelo monitoramento inicial da pesquisa (Figuras 1 e 2).

Quadro 4-Canais selecionados

\begin{tabular}{|l|l|}
\hline Canal & Youtuber \\
\hline Afros e afins & Nátaly Neri \\
\hline Alexandrismos & Alexandra Gurgel \\
\hline De pretas & Gabi Oliveira \\
\hline Ellora Haonne & Ellora Haonne \\
\hline JoutJout Prazer & Júlia Tolezano \\
\hline Rayza Nicácio & Rayza Nicácio \\
\hline
\end{tabular}

Fonte: As autoras (2018).

Como exibido nas Figuras 1 e 2, há uma diferença significativa no alcance midiático entre youtubers negras e não negras mesmo com o recorte temática tão semelhantes. Dessa maneira o próximo passo da pesquisa é buscar aproximações e distanciamentos entre os canais, buscando a partir de uma análise comparativa, compreender se o racismo é um fator determinante para que essa diferença de visibilidade aconteça. 


\section{Análise dos dados: a (in)visibilidade das youtubers negras}

Observamos os vídeos publicados nos seis canais no período de novembro/2017 a novembro/2018. Compreendendo que há fatores externos que poderiam interferir na análise, buscamos aproximações entre os canais para realizar as análises comparativas, sendo assim, definimos: Afros e afins x Alexandrismos, De Pretas x Ellora Haonne e JoutJout Prazer x Rayza Nicácio. A partir do estudo descritivo ${ }^{26}$ que tem o objetivo de expor características e assim estabelecer relações entre as variáveis, a análise parte da observação de três categorias comparativas, a primeira é a de a) alcance, considerando que as influências dos criadores de conteúdo é medida geralmente pelos seus números de alcance, likes, views, deslikes, comentários. A segunda é a b) interação, visto que a base do YouTube é a cultura participativa por meio da interação entre os youtubers e sua audiência, e a terceira é a c) temática, analisando sob o viés interseccional, observamos as falas das youtubers e as subjetividades inseridas nos vídeos.

\section{Análise 1: Afros e afins X Alexandrismos}

O canal Afros e afins pertence à paulista e cientista social em formação Nátaly Neri que já acumula algumas conquistas em seu canal, e a maior delas foi conseguir chegar em espaços que historicamente sua voz não chegaria, além de a influência positiva do seu trabalho ${ }^{27}$.O canal Alexandrismos é comandado pela jornalista Alexandra Gurgel, que praticamente durante toda a sua vida precisou lidar com situações relacionadas a gordofobia, e encontrou no seu canal no YouTube, uma maneira de lidar com essas questões ${ }^{28}$. A escolha da análise entre os dois canais se deu a partir da aproximação dos dados de inscritos e visualizações gerais (Quadro 5).

Quadro 5-Estatísticas gerais: Afros e afins x Alexandrismos

\begin{tabular}{|l|l|l|l|l|l|}
\hline Canal & Início & $\begin{array}{l}\text { Qtd. de } \\
\text { vídeos }\end{array}$ & $\begin{array}{l}\text { Qtd. de vídeos } \\
\text { nov/17 a nov/18 }\end{array}$ & Inscritos & Visualizações \\
\hline Afros e afins & $22 / 07 / 2015$ & 208 & 60 & $518371 \mathrm{mil}$ & 21241305 milhões \\
\hline Alexandrismos & $9 / 10 / 2015$ & 394 & 131 & $441410 \mathrm{mil}$ & 22710935 milhões \\
\hline
\end{tabular}

Fonte: As autoras (2019).

Após observá-los durante o período de novembro/2017 a novembro/2018, identificamos os vídeos mais assistidos (Quadro 6) e, em sequência, pudemos visualizar os dados de alcance de cada um, além de identificar a aproximação das temáticas abordadas.

Quadro 6 - Vídeos mais assistidos: Afros e afins x Alexandrismos

\begin{tabular}{|l|l|l|l|l|l|}
\hline Canal & Vídeo & Visualizações & Likes & Deslikes & Comentários \\
\hline Afros e afins & $\begin{array}{l}\text { Uma semana sem make } \\
\text { e cabelo natural: Um } \\
\text { experimento \#7diasdeescolha }\end{array}$ & $529.675 \mathrm{mil}$ & $59 \mathrm{mil}$ & 757 & $3.979 \mathrm{mil}$ \\
\hline Alexandrismos & $\begin{array}{l}\text { Resposta à Karyna Rangel: Pelo } \\
\text { "direito" de ser artificial }\end{array}$ & $732.342 \mathrm{mil}$ & $98 \mathrm{mil}$ & $6 \mathrm{mil}$ & $6.636 \mathrm{mil}$ \\
\hline
\end{tabular}

Fonte: As autoras (2019). 
Os vídeos se aproximam por meio da temática abordada, a discussão do empoderamento e da autoestima das mulheres acaba sendo um ponto central. A ideia de empoderamento a partir de ações que buscam mudanças individuais e coletivas ${ }^{13}$ está inserida nas falas das youtubers. Por meio de confronto dos padrões de beleza ditos como ideais, elas questionam e refletem em torno das implicações desse padrão em suas vidas, porém, a partir de lugares diferentes ${ }^{29}$. Nátaly, enquanto mulher negra e magra, e Alexandra, enquanto mulher branda e gorda, refletem a partir de seus lugares, mas seus discursos se unem para confrontar o ideal dominante da busca da imagem da mulher ideal. Elas se apropriam das novas tecnologias e do ciberespaço para disseminar e discutir suas subjetividades, compreendendo que a partir da intersecção dos seus marcadores diferenças, outras opressões podem ser originadas. As discussões abordadas pelas duas youtubers podem de fato ser ouvidas e entendidas por mulheres de raça, corpos e classes diferentes, salientando que os modos de entendimento dessas mulheres irão mudar de acordo com suas vivências e as representações que possuem de si mesmas.

A partir do entendimento de que a base do YouTube é a cultura participativa ${ }^{30}$, e a interação entre os produtores de conteúdo e sua audiência é o diferencial da plataforma, se faz interessante expor a interação das youtubers e seus inscritos. Levando em consideração que a interação dentro da rede social só pode acontecer por meio dos comentários, observamos o espaço destinado a comentários dos vídeos e visualizamos os seguintes dados.

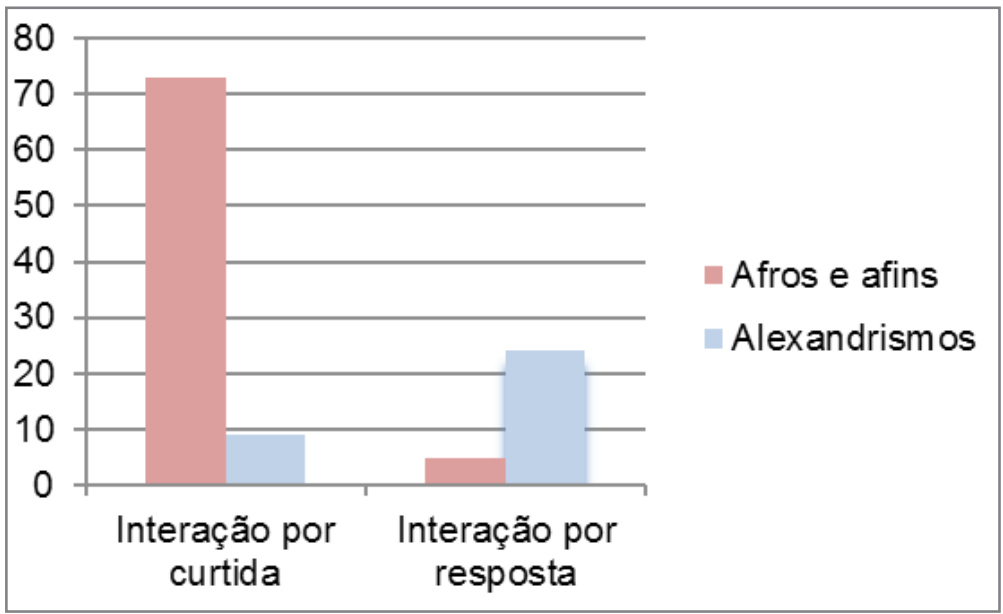

Figura 4 - Interações: Afros e afins x Alexandrismos Fonte: As autoras (2019).

No caso dos dois vídeos observados, a interação por parte das youtubers se deu apenas nos comentários que iam de encontro com suas falas. Dessa maneira, identificamos uma quantidade significativa de comentários que estão vinculados ao sentimento de aproximação e pertencimento, além disso também visualizamos uma diferença significativa entre as interações das youtubers com sua audiência, visto que no aspecto de curtida, Natály interagiu mais do que Alexandra, porém observamos o contrário no aspecto da interação por resposta, apesar da diferença ser inferior.

\section{Análise 2: De Pretas x Ellora Haonne}

A youtuber Gabi Oliveira é carioca e formada em Relações Públicas, e foi após sua monografia sobre o 'Papel das redes sociais na valorização da estética negra' que surgiu a ideia de criar um blog, que em seguida virou canal no Youtube, unindo seus conhecimentos acadêmicos e falando sobre temáticas negras de forma bemhumorada. Já a youtuber Ellora Haonne é uma jovem influenciadora digital que aborda em seu canal temas sobre relacionamento, comportamento, estética, autoaceitação, feminismo e empoderamento. Abordando os temas de forma bastante intimista, Ellora consegue explicitar um pouco sobre sua história e especificidades. 
Quadro 7-Estatísticas gerais: De Pretas x Ellora Haonne

\begin{tabular}{|l|l|l|l|l|l|}
\hline Canal & Início & $\begin{array}{l}\text { Qtd. de } \\
\text { vídeos }\end{array}$ & $\begin{array}{l}\text { Qtd. de vídeos } \\
\text { nov/17 a nov/18 }\end{array}$ & Inscritos & Visualizações \\
\hline De Pretas & $19 / 07 / 2015$ & 228 & 65 & 423711 mil & 13889172 milhões \\
\hline Ellora Haonne & $25 / 02 / 2009$ & 246 & 100 & 1327189 milhão & 55431728 milhões \\
\hline
\end{tabular}

Fonte: As autoras (2019).

A definição da análise entre os dois canais se deu pela aproximação da temática dos vídeos mais assistidos. A tag "Tour pelo meu corpo", criada pela youtuber Luiza Junqueira, propõe mostrar em vídeo as partes do corpo que incomodavam ou ainda incomodam, com o objetivo de expor as implicações desse padrão de beleza estabelecido na sociedade na vida de várias mulheres. O vídeo de Ellora não só exibe essas partes do corpo, como também expõe a diferença do corpo real e o das fotos publicadas em outras redes sociais. Enquanto Gabi, que admite não possuir uma relação problemática com o seu corpo, decidiu produzir um vídeo a partir de seu contexto como mulher negra e fazer um tour pelo seu rosto, mostrando cada detalhe que anteriormente era incômodo, por se tratar de traços da estética negra, mas que hoje possuem um sentido diferente para si.

Quadro 8 - Vídeos mais assistidos: De Pretas x Ellora Haonne

\begin{tabular}{|l|l|l|l|l|l|}
\hline Canal & Vídeo & Visualizações & Likes & Deslikes & Comentários \\
\hline De Pretas & Tour pelo meu rosto & 709.980 mil & 112 mil & 825 & 10.677 mil \\
\hline $\begin{array}{l}\text { Ellora } \\
\text { Haonne }\end{array}$ & $\begin{array}{l}\text { Tour pelo meu corpo - } \\
\text { expectativa vs. Realidade }\end{array}$ & 4.074 .563 milhões & $384 \mathrm{mil}$ & $5 \mathrm{mil}$ & $16.498 \mathrm{mil}$ \\
\hline
\end{tabular}

Fonte: As autoras (2019).

Nesse quadro também está claro que há uma grande diferença entre o alcance de cada vídeo. Mesmo utilizando-se da mesma tag e participando do mesmo momento, é indiscutível que o vídeo de Ellora ganhou uma repercussão muito superior ao de Gabi. Interessante perceber que os traços do rosto destacados por Gabi, característicos da estética negra, ultrapassam o contexto específico da negritude no contexto da miscigenação brasileira. Nariz largo, olhos escuros, lábios protuberantes, por exemplo, são algumas das características desvalorizadas que, em boa parte das mulheres brasileiras, miscigenadas, surge como um problema a ser consertado, sobretudo com maquiagem ${ }^{31}$. Nesse sentido, o que faz o vídeo não conseguir alcançar estas mulheres, mas aquele produzido por Ellora (mulher branca e, inclusive, ruiva - característica rara em todo o mundo) ter o número de visualizações quase seis vezes superior? 


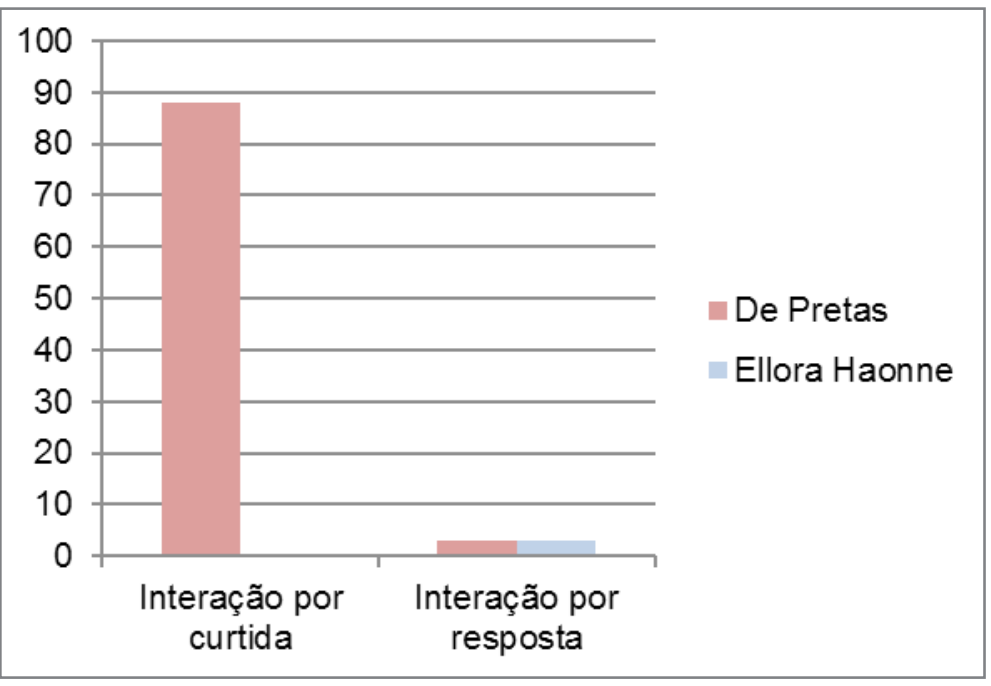

Figura 5 - Interações: De Pretas x Ellora Haonne Fonte: As autoras (2019).

Na categoria de análise da interação, pudemos observar que no aspecto por resposta há uma aproximação das interações, porém na interação por curtidas não visualizamos nenhuma interação da youtuber Ellora Haonne, o que revela uma diferença significativa nas interações. Levando em consideração a importância da interação entre o produtor de conteúdo e sua audiência, é fundamental destacar que essa diferença nas interações acaba não sendo observada na visibilidade dos vídeos.

\section{Análise 3: JoutJout Prazer x Rayza Nicácio}

Júlia Tolezano é a youtuber por trás do canal JoutJout Prazer. Ela discorre sobre temas diversos utilizando-se sempre do tom bem-humorado. Fala sobre seu cotidiano, relacionamento, seus cachorros, seus amigos e diversas situações nas quais seu bom humor se torna protagonista. A youtuber Rayza Nicácio se tornou referência dentro da plataforma por meio dos seus vídeos de cabelo crespo e cacheado. Falando sobre aceitação do cabelo natural e por meio de vídeos tutoriais, a youtuber ajudou sua audiência a cuidar e amar seus cabelos.

Quadro 9 - Estatísticas gerais:JoutJout Prazer x Rayza Nicácio

\begin{tabular}{|l|l|l|l|l|l|}
\hline Canal & Início & $\begin{array}{l}\text { Qtd. de } \\
\text { vídeos }\end{array}$ & $\begin{array}{l}\text { Qtd. de vídeos } \\
\text { nov/17 a nov/18 }\end{array}$ & Inscritos & Visualizações \\
\hline JoutJout Prazer & $12 / 5 / 2014$ & 487 & 116 & $\begin{array}{l}2,212.194 \\
\text { milhões }\end{array}$ & 268.709 .428 milhões \\
\hline Rayza Nicácio & $25 / 3 / 2009$ & 591 & 90 & $\begin{array}{l}1.692 .339 \\
\text { milhão }\end{array}$ & 111.476 .214 milhões \\
\hline
\end{tabular}

Fonte: As autoras (2019).

A definição da análise dos dois canais se deu pelo aspecto de alcance, visto que dentre todos os canais aqui definidos, Júlia e Rayza possuem os maiores números de visibilidade. Devido à diversidade de temáticas abordadas pelas youtubers, os vídeos analisados não são os mais assistidos no período aqui citado, mas são os mais assistidos de cada canal levando em consideração a temática do empoderamento e autoestima. Essa escolha se deu para que pudéssemos aproximar as características e afastar aspectos que pudessem interferir na análise. 
Quadro 10 - Vídeos mais assistidos por temática: JoutJout Prazer x Rayza Nicácio

\begin{tabular}{|l|l|l|l|l|l|}
\hline Canal & Vídeo & Visualizações & Likes & Deslikes & Comentários \\
\hline JoutJout Prazer & $\begin{array}{l}\text { Tá, mas como faz isso de se } \\
\text { amar? }\end{array}$ & 1.105 .470 & 133 mil & 586 & 4.709 \\
\hline Rayza Nicácio & $\begin{array}{l}\text { O vídeo mais sincero desse } \\
\text { canal... }\end{array}$ & 452.263 & 60 mil & 683 & 3.608 \\
\hline
\end{tabular}

Fonte: As autoras (2019).

O vídeo de Rayza Nicácio traz como ponto central a autoestima a partir da aceitação do cabelo natural, apesar de geralmente relacionarmos esse conteúdo ao público de mulheres negras, a youtuber ressalta que sua fala são para todas as mulheres, independentes de sua raça ou etnia. O vídeo de Júlia também prevê uma percepção de neutralidade ${ }^{12}$, ao propor uma análise da autoestima feminina em suas generalizações. No entanto, seu lugar de fala ${ }^{29} \mathrm{e}$ suas percepções sobre as escolhas femininas já inserem nuances de privilégios que podem passar despercebidas. A própria possibilidade de escolha (sobre os locais que frequenta e as pessoas com que se relaciona, por exemplo, que seriam formas de manutenção da autoestima segundo a youtuber) já traz marcadores de raça e classe. A quem é permitido fazer sempre essas escolhas senão à branquitude?

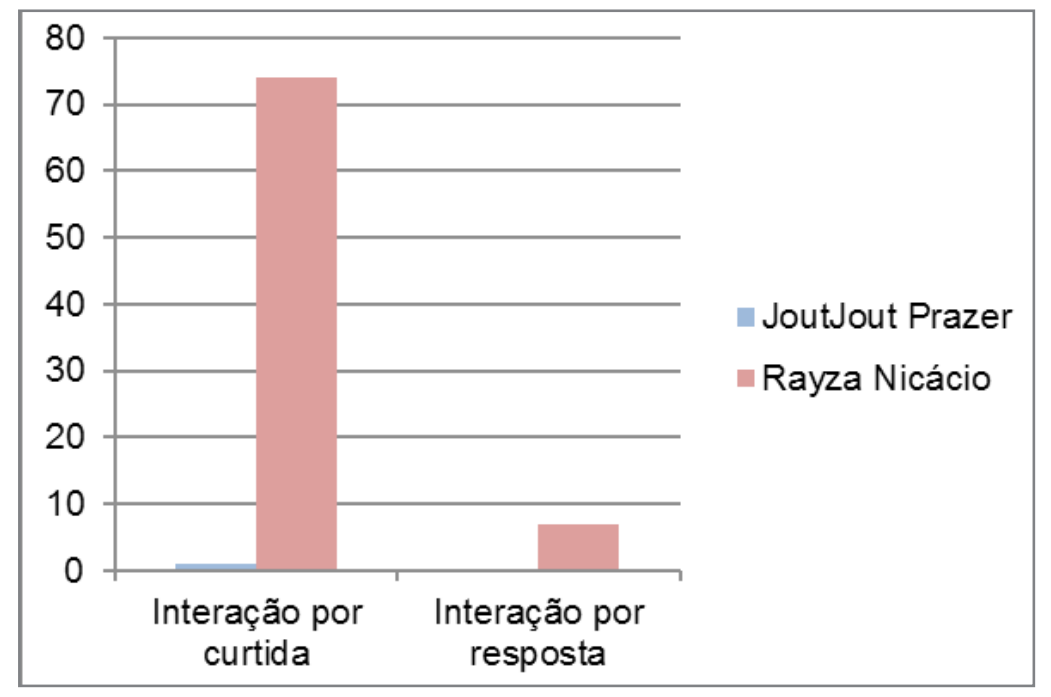

Figura 6 - Interações:JoutJout Prazer x Rayza Nicácio Fonte: As autoras (2019).

É importante destacar que praticamente não há interação de Júlia em comparação com Rayza, e que novamente esse dado não interfere nos dados de alcance de cada canal. É interessante notar, no contexto geral dos dois canais que, embora o de Rayza tenha sido criado cinco anos antes, o canal da youtuber Júlia conseguiu transbordar as fronteiras do digital e alcançar espaços midiatizados tradicionais, sendo convidada para diversas entrevistas, debates e programas televisivos, por exemplo. A possibilidade de ser vista nestes espaços, aliás, pode ser um dos fatores importantes para o aumento da sua influência e popularidade. 


\section{Considerações finais}

É inegável que os sites de redes sociais são espaço importante para a propagação de discursos em prol da luta por reconhecimento e igualdade. As pautas LGBTQ+, o feminismo, o movimento negro e as lutas antirracismo estão usufruindo dessas potencialidades comunicacionais e da cultura participativa para discutir suas questões e levantar reivindicações relevantes. As narrativas das mulheres negras, nesse contexto, estão ganhando espaço em diversas redes sociais: no Facebook e Instagram, podemos ver grupos e indivíduos que discutem a estética e a questão da transição capilar; no Youtube, a discussão do feminismo negro vem ganhando bastante produtoras de conteúdo e consumidoras; assim como no Twitter, as hashtags \#blacktwitter ou \#afrosegueafro vêm ganhando cada vez mais adeptos e repercussão.

No entanto, ainda é problemático pensar sobre visibilidade e alcance de conteúdos produzidos por sujeitos negros. No contexto feminino, percebe-se que mulheres negras ainda enfrentam dificuldade em obter alcance de visualização e engajamento equivalente às mulheres não negras. Realizamos aqui uma análise descritiva dos principais canais do Youtube no contexto brasileiro, delimitando a análise para vídeos com temáticas semelhantes dentro da questão da autoaceitação e autoestima. A partir dos dados coletados, pudemos observar que as mulheres negras tendem a alcançar menores números e, inclusive, menos possibilidade de transbordamento midiático.

Compreender como as falas que ali estão sendo inseridas por meio das subjetividades dos sujeitos negros pode transformar ou traçar novas perspectivas para determinadas minorias.Faz-se necessário pensar nas novas perspectivas ao delimitarmos o Youtube como uma ferramenta didática, já que atualmente inúmeras crianças e adolescentes almejam a profissão youtuber para seu futuro. Por isso um dos principais desdobramentos dessa pesquisa é pensar na rede social Youtube, como um espaço de educação e ressignificação das representações e falas.

A autoaceitação como ferramenta de empoderamento individual é colocada como prêmio às mulheres que conseguem atravessar esse campo de pressões e estabelecer um diálogo consigo mesmo e com seus semelhantes. As mulheres que recorrem às novas mídias para dialogar e transformar as novas imagens de representações levam em sua fala um processo de lidar com o coletivo, mas que coletivo é esse? As mulheres em sua total pluralidade estão sendo representadas nesses discursos?

A branquitude é vista e ouvida dentro do imaginário social por meio de um discurso universal, no mesmo ambiente onde sujeitos negros são representados como minoria, como o "outro" ${ }^{2}$, e a mulher negra como "o outro do outro" ${ }^{2}$. Essas representações estão inseridas de forma direta no consumo cultural, na definição de direitos, por isso é preciso que crianças e adolescentes negros se vejam representados nas mídias, que crianças e adolescentes não negros enxerguem a diversidade e não apenas a branquitude como contexto universal, só assim pessoas negras terão suas subjetividades ouvidas e consumidas.

\section{Referências}

1. Jenkins H. Cultura da convergência. São Paulo: Aleph; 2008.

2. Magnoni AF, Miranda GV. Novas formas de comunicação no século XXI: o fenômeno da cultura participativa. Conexão Comun Cult [Internet] 2013 [citado em 25 out. 2019]:12(23):103-120. Disponível em: http://www.ucs.br/etc/revistas/index.php/conexao/article/view/2226.

3. Almeida SL. O que é racismo estrutural? Belo Horizonte: Letramento; 2018.

4. Hooks B. Olhares negros: raça e representação. Borges S, tradutor. São Paulo: Elefante; 2019.

5. Munanga K. Rediscutindo a mestiçagem no Brasil: identidade nacional versus identidade negra. Petrópolis: Vozes; 1999.

6. Recuero R. Redes sociais na internet. Porto Alegre: Sulina; 2009. 
7. Horochovski RR, Meirelles G. Problematizando o conceito de empoderamento. In: Anais do $2^{\circ}$ Seminário Nacional Movimentos Sociais, Participação e Democracia; 2007 abr. 25-27. Florianópolis: UFSC; 2007 [citado em 25 out. 2019]. Disponível em: https://bit.ly/2oufym3.

8. $\quad$ Carneiro S. Enegrecer o feminismo: a situação da mulher negra na América Latina a partir de uma perspectiva de gênero. In: Takano A. Racismos contemporâneos. Rio de Janeiro: Takano; 2003.

9. $\quad$ Lévy P. Cibercultura. São Paulo: Editora 34; 2009.

10. Malini F, Antoun H. at Internet e hashtag rua: ciberativismo e mobilização nas redes sociais. Porto Alegre: Sulina; 2013.

11. População chega a 205,5 milhões, com menos brancos e mais pardos e pretos. Agência Notícias IBGE [Internet]. 2017 nov. 24 [citado em 2 ago. 2018]. Disponível em: https://bit.ly/368ZB5A.

12. Schucman LV. Entre o encardido, o branco e o branquíssimo: raça, hierarquia e poder na construção da branquitude paulistana [tese na Internet]. São Paulo: Universidade de São Paulo; 2012 [citado em 25 out. 2019]. Disponível em: https://bit.ly/2BTM04d.

13. Berth J. O que é empoderamento? Belo Horizonte: Letramento; 2018.

14. Geledés: Instituto da Mulher Negra. Missão institucional [citado em 14 maio 2018]. São Paulo: 0 Instituto. Disponível em: https://www.geledes.org.br/geledes-missao-institucional/.

15. Davis A. Mulheres, raça e classe. São Paulo: Boitempo; 2016.

16. Davis A, Dent G. A prisão como fronteira: uma conversa sobre gênero, globalização e punição. Rev Est Feministas [Internet]. 2003 [citado em 25 out. 2019]:11(2): 523-531. doi: https://doi.org/10.1590/ S0104-026X2003000200011.

17. Christofoletti R, Watzko RC. Mulheres negras nos jornais: exclusão, gênero e etnia. Rev FAMECOS [Internet]. 2009 [citado em 25 out. 2019]:16(39):98-104. doi: http://dx.doi.org/10.15448/19803729.2009.39.5849.

18. Borges TRS. Por um sentir crítico: um olhar feminista interseccional sobre a socioconstrução de identidades sociais de gênero, raça/etnia e classe de professores de línguas [dissertação na Internet]. Rio de Janeiro: Pontifícia Universidade Católica do Rio de Janeiro; 2017 [acesso em 25 out. 2019]. Disponível em: https://www.maxwell.vrac.puc-rio.br/33770/33770.PDF.

19. Crenshaw K. A interseccionalidade na discriminação de raça e gênero. In: Formação em Direitos Humanos [Internet]. São Paulo: Ação Educativa; set. 2012 [citado em 25 out. 2019]. Disponível em https://bit.ly/2MUhZHP.

20. Collins P, Bilge S. Intersectionality. Cambridge: Polity Press; 2016.

21. Sotero EC. Transformações no acesso ao ensino superior brasileiro: algumas implicações para os diferentes grupos de cor e sexo [Internet]. In: Marcondes MM, Pinheiro L, Queiroz C, Querino AC, Valverde D. Dossiê Mulheres Negras: retrato das condições de vida das mulheres negras no Brasil. Brasília: IPEA; 2013 [citado em 25 out. 2019]. p. 35-52. Disponível em: https://bit.ly/2Nqwy55.

22. Blogueiras Negras: informação para fazer a cabeça [Internet]. [Local desconhecido]: o blog; 2018 [citado em 14 maio 2018]. Disponível em http://blogueirasnegras.org/.

23. Freire P. Conscientização: teoria e prática da libertação: uma introdução ao pensamento de Paulo Freire. São Paulo: Centauro; 2001.

24. Ribeiro D. Quem tem medo do feminismo negro? São Paulo: Companhia das Letras; 2018.

25. Farias LA. Comunicação e feminismo: Experiências ciberfeministas no Brasil [dissertação na Internet]. Salvador: Universidade Federal da Bahia; 2015 [acesso em 25 out. 2019]. Disponível em: https:// repositorio.ufba.br/ri/handle/ri/25659.

26. Gil AC. Como elaborar projetos de pesquisa. São Paulo: Atlas; 2002.

27. Conheça Nátaly Neri a youtuber que mostra que engajamento e moda tem tudo a ver. Elle [Abril] [Internet]. 2016 jun. 08 [citado 10 jun. 2018]. Disponível em: https://elle.abril.com.br/moda/conhecanataly-neri-a-youtuber-que-mostra-que-engajamento-e-moda-tem-tudo-a-ver

28. Lemos V. 'A gente não quer mais ser visto como doente': a vida de quem é alvo de gordofobia. BBC News Brasil [BBC] [Internet] 2017 dez. 24 [citado 20 maio 2019]. Disponível em: https://www.bbc.com/ portuguese/brasil-42446726. 
29. Ribeiro D. O que é lugar de fala? Belo Horizonte: Letramento; 2017.

30. Burgess J, Green J. YouTube e a revolução digital: como o maior fenômeno da cultura participativa transformou a mídia e a sociedade. São Paulo: Aleph; 2009.

31. Gomes NL. Corpo e cabelo como símbolos da identidade negra [tese]. São Paulo: Universidade de São Paulo; 2002.

32. Kilomba G. Memórias da plantação: episódios de racismo cotidiano. Rio de Janeiro: Cobogó; 2019. 